\title{
Grack propagation and fracture resistance in saline ice
}

\author{
SAMUEL J. DEFRANCO* AND JOHN P. DEMPSEY \\ Department of Civil and Environmental Engineering, Clarkson University, Potsdam, New York 13699-5710, U.S.A.
}

\begin{abstract}
Crack propagation in saline ice (a model sea ice) is investigated in this study in an attempt to understand the processes of crack growth at one loading rate and two temperatures. As has been previously observed in cold sea ice and warm or cold fresh-water ice, crack growth occurs in initiation/arrest increments. The energetic stability criteria of crack growth are examined in saline ice and crack growth is characterized in terms of the fracture-resistance parameter $K_{\mathrm{R}}$. This paper offers the development of a new fracture geometry capable of sustained stable crack growth and the presentation of fracture-resistance curves for saline ice at $-25^{\circ}$ and $-15^{\circ} \mathrm{C}$. The important findings of this paper are that: (i) in warm saline ice, extensive local crack-tip damage is accompanied by a limited amount of slow, stable crack extension; (ii) fracture in cold saline ice is characterized by locally negative $K_{\mathrm{R}}$ behavior; and (iii) fracture in cold or warm saline ice is characterized by globally
positive $K_{\mathrm{R}}$ curve behavior.
\end{abstract}

\section{INTRODUGTION}

The primary failure mechanism of Arctic ice sheets is fracture. Crack initiation and propagation in ice sheets form the basis of many models of ice structure/interaction, the formation of pressure ridges, rubble fields and leads as well as the acoustic emission associated with field-scale deformations of ice. Fracture is generally taken for granted in the aforementioned models due in part to the limited amount of relevant studies in the ice literature. Consequently, little or no emphasis has been placed on quantifying the specific physical mechanisms of cracking in ice.

Recent investigations into ice-floe splitting (Bhat, 1988; Bhat and others, 1989) used the finite-element method to investigate the failure of summer ice floes through splitting and eventual clearing of the ice floe following impact with an offshore structure. The crux of the analysis by Bhat (1988) is the assumption that a single, large crack will form and grow stably until a critical length is obtained. At the critical crack length, unstable extension of the crack occurs, allowing complete unloading of the structure. During stable-crack extension, the load that the structure must resist is assumed to increase monotonically until a maximum load, which corresponds to the onset of unstable fracture, is reached. However, no specific material parameter allowing or disallowing stable fracturing is included. Additionally, assuming a crack can propagate slowly in ice, when does the onset of unstable, rapid cracking occur?

Thermal fluctuations, and the effects of ocean currents and winds, all build up internal stresses within an ice sheet. These stresses are relieved by the formation of

\footnotetext{
- Present address: Amoco Production Company, 4502 East 41st Street, P.O. Box 3385, Tulsa, Oklahoma 74102-3385, U.S.A.
}

pressure ridges, rubble fields and leads. Assur (1963) discussed his so-called "long-wave cracks" which possess sufficient kinetic energy to extend rapidly for hundreds of kilometers, propagating through first-year as well as multi-year pressure ridges. Assur also noted that the "long-wave cracks" completely disregard the thickness and shape of ice floes in their crack path, cutting right through them. As in the previous example, the processes associated with the formation and propagation of longwave cracks were not specified.

Currently, studies are being performed in order to relate recorded acoustic emission events to the occurrence of crack formation in Arctic ice sheets (Dyer, 1988; Farmer and Xie, 1989; Xie and Farmer, 1991). Farmer and Xie (1989) used theory developed for earthquake engineering which is relevant to ice cracking, albeit on a much larger scale. To model their recorded data, cracking is assumed to occur incrementally; crack growth of this type is usually called "stick-slip" or incremental cracking, and in earthquake mechanics is assumed to be controlled by the narrowest dimension of the crack plane. It is important to note that "stick-slip" cracking has been observed previously in experiments on fresh-water and sea ice.

The aim of this paper is to investigate cracking in saline ice at temperatures above and below the eutectic point of $-21.2^{\circ} \mathrm{C}$ for this ice and at a slow loading rate. The primary objectives are (1) to examine the geometric conditions under which stable cracking can and cannot occur, and (2) to establish a crack initiation/propagation parameter which is capable of delineating the stable to unstable transition which occurs during crack growth. In the context of this paper, it is understood that, prior to crack initiation, there may be sub-critical crack growth for $K_{\mathrm{I}}<K_{\mathrm{Ic}}$. This paper does not address sub-critical cracking nor does it address any effects of crack healing. The term "stable crack growth" here implies quasi-static 
crack growth which would arrest if the applied loads were released.

\section{GRACK-INITIATION AND PROPAGATION PARAMETERS}

Catastrophic crack propagation may, depending on size scales involved, be quantified by the plain-strain fracture toughness $K_{\text {Ic }}$ - a parameter which describes the unstable initiation of a crack and is, by definition, a material property. During ice/structure interaction, however, contact between an ice sheet and an offshore structure often results in the accumulation of damage in the contact zone. In some cases, a limited amount of slow crack growth may occur under increasing load before unstable crack extension and ultimate failure of the ice sheet. This type of fracture cannot be quantified solely by $K_{\text {Ic }}$; instead, a different approach based on the energyabsorption capability of the material with crack growth is necessary. The fracture resistance or so-called $R$-curve method is an appropriate parameter as it measures directly the energy needed for crack growth.

Irwin and Kies (1954) discussed several anomalies associated with fracture instabilities in metal plates; often, during the loading of cracked plates, load vs displacement curves of these plates were linear until near the peak load. Near the peak load, limited ductility occurred followed by rapid fracture of the plate. In other instances, a large amount of ductility was observed prior to unstable cracking of the plate. To account for these quite different behaviors, it was postulated by Irwin and Kies (1954) that the work rate of fracture $R=\partial W / \partial a$, where $W$ is the fracture work and $a$ is the current crack length, is a continuously decreasing function of the crack length. The work rate of fracture is also called the fracture resistance of the material and represents the energy dissipated at the crack tip during fracture. If the strain-energy release rate $G_{\mathrm{c}}$ (the crack driving energy arising from applied mechanical energy) increases with crack length while the fracture resistance decreases, the increasing amount of energy in the system causes increased crack speed leading to a change from ductile tearing to rapid fracture. For continued stable cracking, Irwin and Kies presumed a near match of $G$ and $R$ must exist. In a later paper, an ASTM Special Committee Report (1960) altered the previous fracture-resistance concept to include the possibility of increasing fracture resistance with crack extension. Implications of both increasing and decreasing $R$ with crack growth as well as the geometry dependence of $G_{\mathrm{c}}$ will be examined in detail in a later section.

With regard to ice fracture, many studies exist in the literature concerning loading rate and temperature effects on the initiation toughness $K_{\text {Ic }}$ of ice; crack propagation and crack-growth stability, however, have received only limited attention (Dempsey and others, 1986; Bentley, 1988; Parsons and others, 1988, 1989; DeFranco and Dempsey, 1990, 1991; Stehn, 1990, 1991). The difficulty in performing crack-propagation experiments in ice is not generally appreciated, as non-standard fracture-test specimens must be used in order to obtain conditions conducive to stable crack growth. Dempsey and others (1986) and Bentley (1988) used the tapered double- cantilevered beam specimen. Parsons and others (1988, 1989) used the constant $K$ double-torsion (DT) geometry in order to study slow crack growth in ice while DeFranco and Dempsey (1990) used the compression-loaded doublecantilever beam geometry or CFDCB (Kendall, 1978) to examine crack-growth stability in S2 fresh-water ice. Using Kanninen's (1973) idealization of the uncracked ligament as an elastic Winkler foundation, DeFranco and Dempsey (1990) explained the crack-length effects observed by Kendall (1978) during fracture tests on several brittle materials. Recently, the round chevron notched specimen (used frequently for fracture studies on rock) was used for fracture experiments on brackish sea ice (Stehn, 1990, 1991). Despite the attempts by the previously mentioned studies to produce stable cracking in ice, all reported incremental or so-called "stick-slip" cracking. "Stick-slip" cracking consists of unstable crack initiation followed by sudden crack arrest. To restart cracking, the applied load must be increased. The reasons for "stick-slip" cracking can, in part, be explained in terms of the shape of the fracture-resistance curve with crack extension and its dependence on crack velocity; additionally, the occurrence of stable cracking is partially dependent on the experimental geometry.

\section{CRACK-GROWTH STABILITY BY $R$-GURVE ANALYSIS}

For a crack to propagate in a medium, the crack-driving energy $G=\partial U_{\mathrm{t}} / \partial a$, where $U_{\mathrm{t}}$ is the total mechanical energy, must equal the material's resistance to fracture $R$. In a purely brittle material, $R$ consists solely of the energy required to create new surface area or $R=2 \gamma$. This condition is known as the Griffith criterion and is often written as $G_{\mathrm{c}}=2 \gamma$. In ice, however, polycrystalline effects as well as creep effects at the crack tip cause the experimentally determined critical energy-release rate $G_{\mathrm{c}}$ to be higher than the specific surface energy. Gold (1963), in a pioneering study, calculated the strain-energy release rate at crack arrest for fresh-water columnar ice using a thermal-shock technique in order to induce cracks in the ice. He found that at arrest, $G_{c}^{\text {arrest }}$ ranged from a minimum of approximately $0.20 \mathrm{~J} \mathrm{~m}^{-2}$ to a maximum of approximately $4 \mathrm{~J} \mathrm{~m}^{-2}$ depending upon the size of the segments between the thermally induced cracks. Dempsey and others (1989) measured the critical energy-release rate $G_{\text {Ic }}$ of fresh-water columnar ice using a wedge-loaded compact tension specimen finding an ultimate plateau $G_{\mathrm{Ic}}$ of $0.60 \mathrm{~J} \mathrm{~m}^{-2}$ for the largest size tested. For ice, the specific free-surface energy $\gamma$ along an easy cleavage plane of a pure fresh-water single crystal at $0^{\circ} \mathrm{C}$ is given by $\gamma_{\mathrm{sv}}=0.109 \mathrm{~J} \mathrm{~m}^{-2}$; the associated energy along a grain boundary is given by $\gamma_{\mathrm{gb}}=0.065 \mathrm{~J} \mathrm{~m}^{-2}$ (Ketcham and Hobbs, 1969). These values for the surface energy were determined from groove-angle measurements and may not represent the true fracture energy released during fracture of a single ice crystal. Further, the data of Dempsey and others (1989) on S2 columnar ice are polycrystalline values representing the coupled behavior of a collection of ice crystals - in terms of size, these data reflect the size of the test specimen used and may be unrepresentative of large-scale field behavior as well as for 
a microcrack precursor on the microstructural scale. Given that ice is not an ideally brittle solid, the IrwinOrowan generalization of the Griffith equilibrium condition is $G_{\mathrm{c}}=R$ (often written as $G_{\mathrm{c}}=2 \Gamma$ ).

While the equality of the driving and resisting energies is a necessary condition for crack growth, the rate of change of driving energy must be less than the rate of change of fracture resistance for the crack growth to be stable:

$$
G=R \quad \text { and } \quad \frac{\partial G}{\partial a}<\frac{\partial R}{\partial \Delta a} .
$$

The implications of Equation (1) are illustrated in Figures 1 and 2. Ductile materials such as metals and quasi-brittle materials such as concrete, ceramics and rock often exhibit rising $R$-curve behavior; in other words, the resistance to fracture increases with crack growth $\Delta a$. An increasing $R$ curve is often characterized by a rapidly increasing fracture resistance which levels off to a constant fracture resistance, independent of crack length. This constant fracture resistance is size-independent and is assumed to be a material property. The physical mechanism which causes increased resistance depends on the particular material; in metals subjected to slow loading, for example, the stress intensification caused by a crack is limited by the yield strength and therefore crack extension only occurs following local yielding, void growth and coalescence in the inelastic crack-tip zone (or the so-called fracture-process zone). It is important to note that metals (as well as concrete and rock) subjected to impact loading may fail by brittle, catastrophic fracture; in this paper, only quasi-static loading rates are considered, thus the example of crack-tip yielding in metals serves simply as a contrasting failure mechanism which is not relevant for ice. For concrete, material nonhomogeneity results in an increased fracture resistance due to aggregate interlock, microcrack formation, crack branching, fiber bridging and mortar/aggregate-interface cracking.

The driving energy $G$ is dependent on the shape of the body, the current load $P$ and crack length $a$. In Figure la, a hypothetical rising $R$ curve is shown together with $G$ curves representing the crack-driving energy with crack growth for a positive geometry. A positive geometry (Planas and Elices, 1990) denotes positive $\partial G / \partial a$ behavior which is exhibited by standard fracturemechanics test geometries such as the three-point and four-point bend and the edge-cracked uniaxial tension specimen. At a constant load $P_{1}$, the associated driving energy $G_{1}$ intercepts the $R$ curve at a crack extension $\Delta a_{1}$; at this load, the crack has extended stably an amount $\Delta a_{1}$ such that the crack length is now $a_{1}=a_{0}+\Delta a_{1}$. This trend continues until the peak load $P_{\max }$ where, due to tangency of the $G$ and $R$ curves, Equation (1) is violated and catastrophic failure of the body occurs by unstable fracture at a critical crack length $a_{\mathrm{c}}=a_{0}+\Delta a_{\mathrm{c}}$. Despite the increasing $R$ curve, the positive geometry is incapable of characterizing the whole $R$ curve for this material. In this hypothetical case, a larger specimen size is needed in order to reach the plateau - the size-independent fracture resistance which characterizes the fracture of large, field-scale structures. Peck and others (1985) found that for various types of

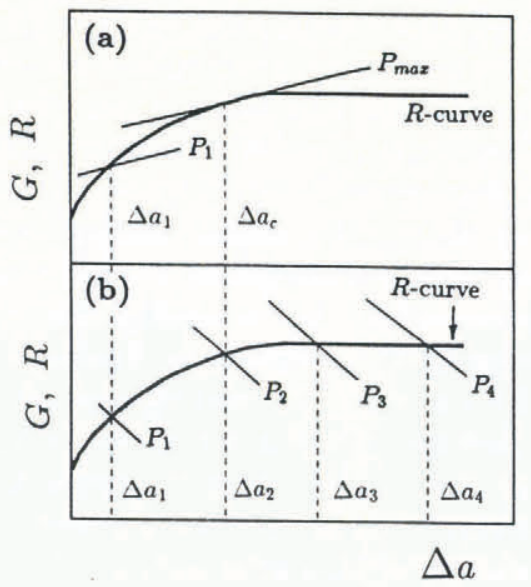

Fig. 1. Fracture behavior using positive vs negative geometry with a positive $R$-curve material: (a) positive $G$; (b) negative $G$.

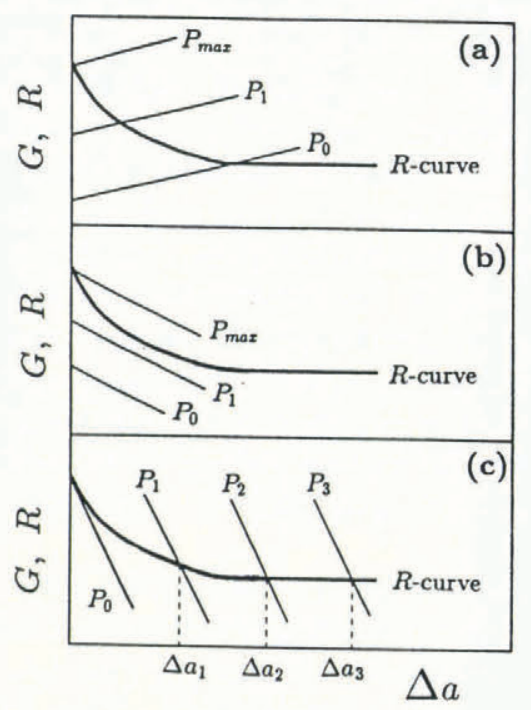

Fig. 2. Fracture behavior using positive vs negative geometry with a negative $R$-curve material: (a) positive $G$; (b) insufficiently negative $G$; (c) sufficiently negative $G$.

rock, the amount of stable crack growth needed to reach a plateau fracture resistance was several times the grainsize. For example, for Dresser basalt (grain-size of 0.04 $\mathrm{mm}$ ), the requisite crack growth for a plateau resistance was found to be 500 times the grain-size. If ice behaves similarly, and due to the huge grain-size relative to rock, a specimen made from ice having an average grain-size of say $15 \mathrm{~mm}$ would need to be at least $7 \mathrm{~m}$ long. In the Arctic, where grains of sea ice can be on the order of $100 \mathrm{~mm}$, a fracture specimen would have to be at least $50 \mathrm{~m}$ in length. Obviously, a laboratory fracture specimen will be greatly sub-sized and a steady-state fracture resistance may well not be achievable.

Stable crack growth is always achieved for materials characterized by a rising, or flat $R$ curve by means of a negative geometry (i.e. negative $\partial G / \partial a$ behavior; Fig. lb). A geometry exhibits negative $\partial G / \partial a$ behavior either by shape influences on the specimen compliance or by artificially stabilizing the geometry with ductile straps (Mai and Atkins, 1980). In Figure 1b, $G$ curves from a negative geometry are shown. By the same arguments as before, at various constant loads $P_{1}$ through $P_{4}$, crack 
growth is always stable as Equation (1) is never violated. In this case, the fracture geometry allows sufficient crack extension for the plateau fracture resistance to be measured. Note that a specimen-size effect is still possible with a negative geometry if the minimum necessary crack growth for the plateau $R$ is unobtainable (Irwin, 1961).

Apparently, stable crack growth is easily obtained for materials characterized by increasing $R$ curves by a judicious choice of an experimental fracture geometry; many materials exhibit stable cracking even with positive geometries, thereby requiring no special testing techniques. For ice, the question remains: even with negative fracture geometries (stable geometric conditions), why does "stick-slip" cracking almost always occur? As saline ice (and sea ice) comprises mainly fresh-water ice, at cold temperatures where the brine pockets are at their smallest size and consequently the air pressure in the brine pockets is maximum, cracking will be dominated by the freshwater ice and will be rate-sensitive (in other words, decreasing fracture resistance with increasing crack velocity.). Large brine channels will in many cases, however, cause crack arrest due to the higher energy needed by the crack to penetrate these barriers. Subsequently, increased external loading is necessary in order to restart the arrested crack, resulting in a jagged load vs time record. In terms of the fracture resistance, following each crack-initiation event, the $R$ curve decreases until crack arrest. Subsequent crack re-initiation occurs at a higher fracture resistance than the previous crack-arrest value and causes a locally decreasing but globally increasing fracture resistance with crack growth.

Unstable cracking in some rate-sensitive materials may be quantified by a negative fracture-resistance curve. In Figure 2, a negative $R$ curve, which was originally proposed for metals (Irwin and Kies, 1954), is shown for various $G$ curves. A negative $R$ curve exhibits decreasing crack resistance with crack growth and may result from the blunting of the stationary crack tip, which, following initiation, sharpens during propagation and increases in speed. At its optimum velocity, the crack tip is atomically sharp and propagates at the lowest fracture energy necessary for propagation until the driving energy drops below the critical value and the crack arrests. Crack-tip heating may also cause unstable cracking by lowering the fracture resistance of the near-tip material. In Figure 2a, a negative $R$ curve is shown with a positive fracture geometry; stable crack growth is never possible as Equation (1) cannot be satisfied. Only unstable crack extension at $G=G_{\mathrm{c}}$ is possible at the maximum load. An insufficiently negative set of $G$ curves is shown in Figure 2b. As with a positive geometry, this negative fracture geometry cannot satisfy Equation (1) and catastrophic fracture occurs at the critical energy-release rate for crack initiation. In order to achieve continued stable cracking, the fracture geometry must match the negativity of the $R$ curve. In Figure 2c, a sufficiently negative fracture geometry enables stable crack growth over the full range of crack extension and complete characterization of the $R$ curve.

To date, a very limited amount of stable cracking has been observed in fresh-water ice but only at very long crack lengths (DeFranco and Dempsey, 1990). Figure 3 in that paper shows the normalized $G$ curve for the CFDCB geometry. Sufficiently negative derivative behavior exists only for very long cracks, verifying analytically the observed cracking as related to the proposed negative $R$ curve. Additionally, DeFranco and Dempsey (1991) observed slow cracking at various crack lengths in saline ice at $-15^{\circ} \mathrm{C}$ using a new fracture geometry, the reversetapered-crack-line wedge load (RT-CLWL). The experiments in that paper and the new fracture geometry are the basis for this work.

In the light of the above discussion and a growing amount of literature indicating observations of both stable and unstable crack growth in fresh-water and sea ice, this paper addresses cracking in ice by examination of the equations of energetic stability as defined in Equation (1) with regard to specimen and testing-machine compliance. An $R$ curve for saline ice is determined through use of a new fracture-testing geometry. Experiments performed at two temperatures $\left(-25^{\circ}\right.$ and $\left.-15^{\circ} \mathrm{C}\right)$ indicate that different fracture mechanisms are operable at each temperature, resulting in very different crackgrowth behavior. Possible physical mechanisms for the apparent temperature-dependence of crack stability are discussed.

\section{ENERGETIC STABILITY IN FRACTURE TESTING}

Gurney and Hunt (1967) noted the functional dependence of $G$ on $a$ greatly influences crack-growth stability - by manipulation of Equation (1) and the well-known specimen-compliance relationship of the energy-release rate,

$$
G=\frac{P^{2} \mathrm{~d} C}{2 h \mathrm{~d} a}
$$

where $P$ is the applied load, $h$ is the specimen thickness and $a$ is the current crack length, they determined for the case of displacement control that

$$
\frac{1}{G} \frac{\mathrm{d} G}{\mathrm{~d} a}=\frac{C^{\prime \prime}}{C^{\prime}}-2 \frac{C^{\prime}}{C}\left(\frac{C}{C+C_{\mathrm{M}}}\right)
$$

In Equation (3), $C, C^{\prime}$ and $C^{\prime \prime}$ are the compliance and the first and second derivatives of the compliance with respect to the crack length $a$. $\bar{C}_{\mathrm{M}}$ is the total compliance of the loading device, while $C_{\mathrm{M}}=\bar{C}_{\mathrm{M}} h$, where $h$ is the specimen thickness. Ideal test geometries are classified as having the desired "geometric stability factor" (hereafter referred to as the GSF) if $\partial G / \partial a$ was negative over an appropriate crack-length interval. In other words, the test geometry must exhibit the GSF to match the fractureresistance behavior $(\mathrm{d} R / \mathrm{d} \Delta a) / R$. As indicated in Equation (3), however, a compliant testing machine increases the GSF and may induce unstable fracture in geometries which are normally stable in a more rigid testing machine. The lack of stable crack growth in the experiments by Dempsey and others (1986) and Bentley (1988) reflected the dependence of testing-system compliance evident in Equation (3). Due to the compliance of the testing carriage used for these experiments, stable cracking was not observed despite the use of a stable geometry and large specimens. 


\section{Example: compression failure of brittle porous solids}

Fracture and failure of quasi-brittle materials subjected to compressive loading is significantly more complicated than the tensile fracture of a single crack. Compressive failure involves the nucleation, propagation and interaction of a large number of microcracks. However, it is widely accepted that, once nucleated, microcracks propagate primarily as tensile (mode I) cracks in a direction parallel to the maximum principal compressive stress. In this context, an understanding of the behavior of a single crack may appear irrelevant. However, the understanding sought in this paper is a necessary first step.

As an example, crack-growth stability for Sammis and Ashby's model for crack extension from a single pore or inclusion in an infinite solid due to axial compression loading and either lateral tension or compression is examined. Sammis and Ashby (1986) modeled the pore or inclusion, in the case examined here, as a cylindrical pore of radius $a$ having symmetrical cracks of length $l$ extending parallel to the direction of applied compressive stress. They determined the approximate mode I stressintensity factor for a cracked, cylindrical pore in an infinite plane to be:

$$
K_{\mathrm{I}}=-\sqrt{L^{*}}\left[\frac{1.1(1-2.1 \lambda)}{\left(1+L^{*}\right)^{3.3}}-\lambda\right] \sigma_{1} \sqrt{\pi a}
$$

where $\sigma_{1}$ is the compressive stress applied in a direction parallel to the crack, $\lambda=\sigma_{3} / \sigma_{1}$ ( $\sigma_{3}$ is the lateral stress), $a$ is the radius of the pore and $L^{*}=l / a$ ( $l$ is the length of the crack extension). Note that $\lambda<0$ implies lateral tension; conversely, $\lambda>0$ implies lateral compression. Neglecting machine compliance and, as $K_{\mathrm{I}}$ and $K_{\mathrm{R}}$ can be used equivalently in Equation (1) instead of $G$ and $R$, respectively, the GSF is:

$$
\begin{aligned}
\mathrm{GSF} & =\frac{1}{K_{\mathrm{I}}} \frac{\partial K_{I}}{\partial L^{*}} \\
& =\frac{1}{2 L^{*}}-\frac{3.63(1-2.1 \lambda)}{\left(1+L^{*}\right)\left(1.1(1-2.1 \lambda)-\lambda\left(1+L^{*}\right)^{3.3}\right)} .
\end{aligned}
$$

The GSF for this model is plotted vs $L^{*}$ in Figure 3 for biaxial stress ratios $\lambda=-0.2,-0.1,0,0.1$ and 0.2 . Sammis and Ashby (1986) observed from model experiments on glass and PMMA that crack initiation always

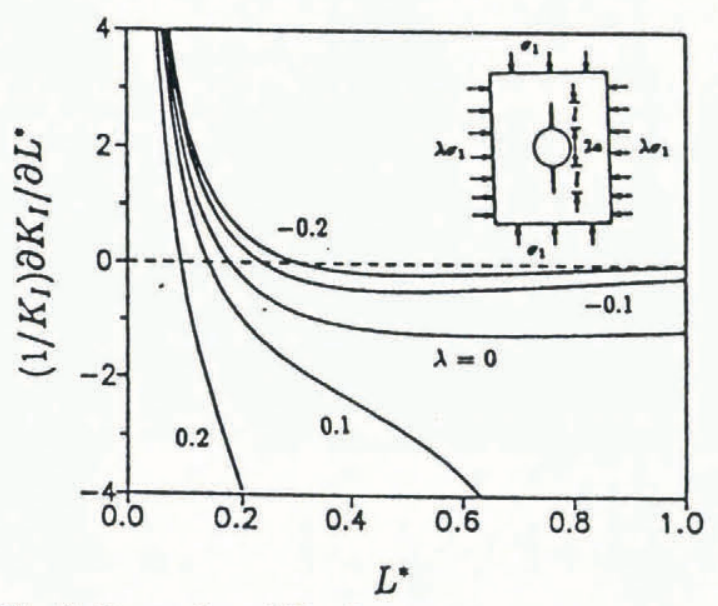

Fig. 3. Geometric stability factor (GSF) for Sammis and Ashby (1986) compression-failure model. occurred as an unstable crack "pop-in". This phenomenon is readily explained by examination of the GSF for this crack geometry: for very short cracks, the GSF is strongly positive, therefore stable cracking will only occur in a material which has a $K_{\mathrm{R}}$ curve which rises rapidly enough to cope with the GSF. Glass, PMMA and most quasi-brittle materials have $K_{\mathrm{R}}$ curves which rise gradually to a plateau resistance $\left(\partial K_{\mathrm{R}} / \partial \Delta L^{*}=0\right)$. Consequently, a crack emanating from a cylindrical pore will propagate unstably after initiation to a crack length which corresponds to a zero GSF (i.e. $\partial K_{\mathrm{I}} / \partial L^{*}$ $<\partial K_{\mathrm{R}} / \partial \Delta L^{*}=0$ for a plateau fracture resistance). For the case of no lateral loading $(\lambda=0)$, the GSF is zero (Fig. 3) at approximately $L^{*}=0.2$ which is exactly the crack "pop-in" length reported by Sammis and Ashby for glass and PMMA.

Finally, it should be noted that the above analysis ignores testing-machine compliance which in a compression test would certainly contribute to crack-growth instability and cause a deviation from the crack "popin" length predicted by this analysis.

\section{Applications to ice fracture}

The application of this concept to ice was first used in Dempsey and others (1986) for a double-cantilever beam (DCB) specimen and later by Parsons and others (1989) using the double-torsion (DT) geometry. Based upon theoretical compliance information, the normalized GSF for the DCB is:

$$
\frac{L}{G} \frac{\mathrm{d} G}{\mathrm{~d} a}=-\frac{2 L}{a}\left(\frac{2-C_{\mathrm{M}} / C}{1+C_{\mathrm{M}} / C}\right)
$$

while for the DT

$$
\frac{L}{G} \frac{\mathrm{d} G}{\mathrm{~d} a}=-\frac{2 L}{a}\left(\frac{C}{C+C_{\mathrm{M}}}\right)
$$

where $L$ is a characteristic geometric dimension of the test geometry. Apparently, crack growth in materials which exhibit increasing, flat or slightly decreasing ( $\mathrm{d} R /$ $\mathrm{d} \Delta a) / R$ behavior should be stable in these configurations.

Parsons and others (1989), using the DT geometry, reported crack jumping in fresh-water ice at $-20^{\circ} \mathrm{C}$ and in field experiments on sea ice performed at temperatures ranging from $-25^{\circ}$ to $-15^{\circ} \mathrm{C}$. Additionally, Selby and Miller (1975) reported crack jumping in an epoxy resin using a forward-tapered cantilevered-beam geometry (a constant $K$ specimen). Examination of the energeticstability equation indicates that "stick-slip" materials may possess locally negative $R$ curves. The observed degree of negativity (or crack-speed dependence) of the $R$ curve is partially dependent on the flexibility of the loading system; even extremely geometrically stable geometries may produce unstable fracture as previously mentioned. However, some remarks regarding negative $R$ behavior can be made in the context of a rigid loading system: for example, if experiments on "stick-slip" materials are performed using a positive or insufficiently negative fracture geometry, a lack of stable crack growth prior to unstable fracture would indicate the inability of the fracture geometry to accommodate the locally negative $R$ curve. This behavior has been consistently observed in fresh-water ice. 
Experiments preliminary to this study were performed by the authors on fresh-water columnar ice using the crack-line wedge-loaded (CLWL) geometry (Heyer and McCabe, 1972). The CLWL geometry is commonly used for determining the $R$ curve of metals and is well known to effect slow crack growth in positive $(\mathrm{d} R / \mathrm{d} \Delta a) / R$ materials. An important feature of the CLWL geometry is the mechanical advantage achieved through wedge loading; the machine load required for crack propagation can be reduced by a factor of up to 5 (ASTM E561$86,1987)$, hence reducing any fracture instabilities created by machine-compliance effects. Crack growth in the preliminary fresh-water ice experiments, however, consisted mainly of long crack jumps that arrested very near the specimen edge. The motivation for a new test geometry was provided by Mai and others (1975), who illustrated that reverse tapering (i.e. decreasing specimen width with increasing crack length) greatly improved crack-growth stability. Additionally, it was found that crack-path stability in reverse tapered geometries was greatly improved from typical forward-tapered, constant$K$ fracture geometries. For this reason, the reversetapered CLWL (RT-CLWL) was developed for fracture-resistance experiments on saline ice (DeFranco and Dempsey, 1991). The specifics of this geometry will be described in detail in the next section.

\section{RT-CLWL FRACTURE GEOMETRY}

Figure 4 shows a schematic of the RT-CLWL geometry. Loading is applied by a wedge which is in contact with two sets of split pins made in accordance with ASTM E561-86. Each split pin consists of a load sector which contacts the specimen and a tapered wedge-load block which fully contacts the loading wedge (see Fig. 5). To ensure proper alignment of the load sectors and the load path, the wedge-load blocks are machined such that line contact exists. Figure 5 shows a schematic of the loading fixture. As the wedge is displaced downward by the crosshead of the test frame, loading is applied by the load sectors and wedge-load blocks, which rest on sliding retainer blocks, which in turn rest on a base block. The wedge, wedge-load blocks and load sectors were constructed of stainless steel and the base block and sliding base block and sliding retained block were constructed

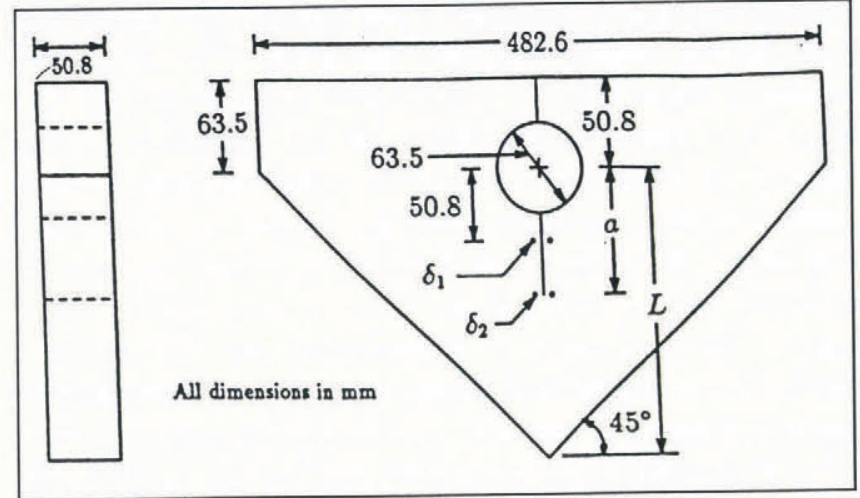

Fig. 4. The reverse tapered-crack-line wedge load (RTCLWL) fracture geometry.

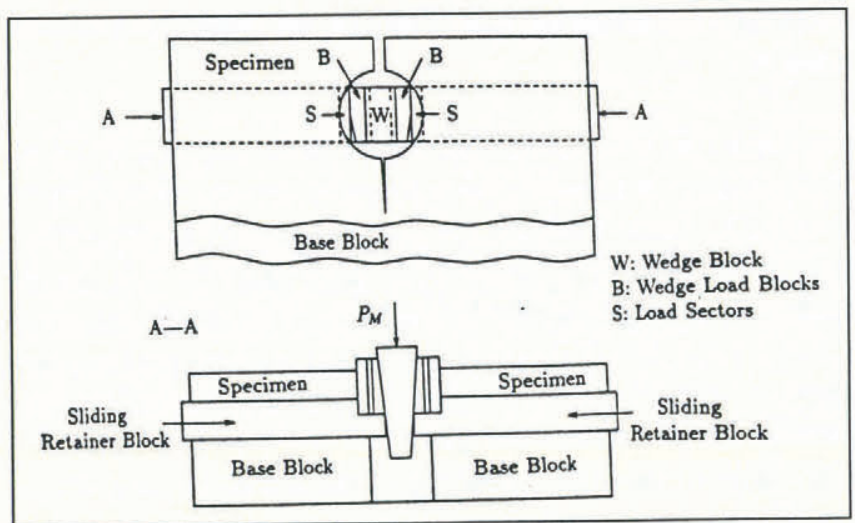

Fig. 5. Wedge-loading apparatus and set-up.

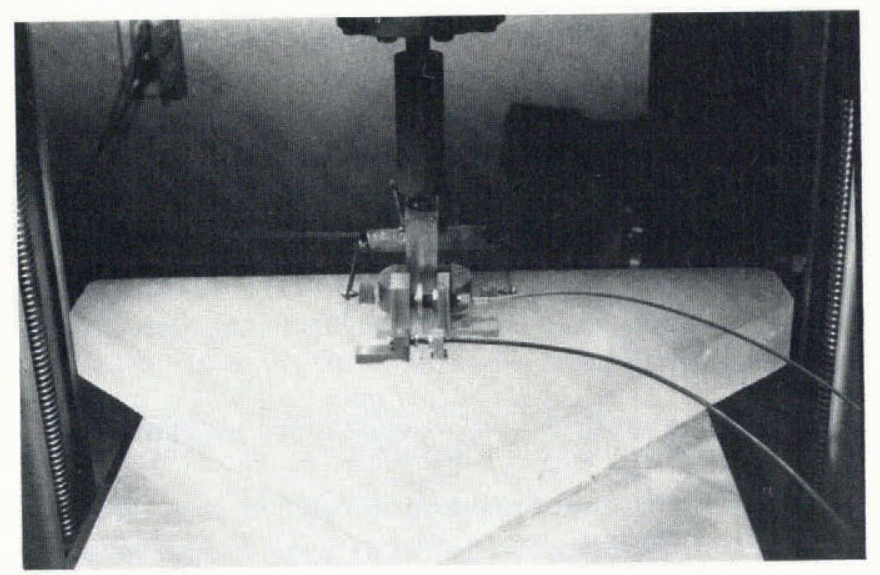

Fig. 6. RT-CLWL specimen ready for testing.

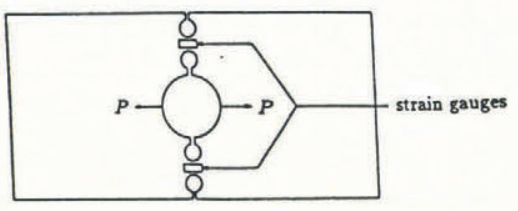

Fig. 7. Schematic of device used for friction analysis.

from 6061-T6 aluminum (Fig. 5). Powdered graphite was used as a lubricant in order to reduce friction between all components. An RT-CLWL specimen ready for testing is shown in Figure 6.

An important parameter to be determined was the friction which exists between the loading components. To accomplish this, a steel plate $(355 \mathrm{~mm} \times 152 \mathrm{~mm} \times 6$ $\mathrm{mm}$ ) was constructed as shown in Figure 7 and loading was applied to the center hole during different trials using either direct tension or wedge loading. Stress concentrators ( $14 \mathrm{~mm}$ diameter holes) were placed along the tension line in order that measurable strains would occur at load levels similar to those experienced during an icefracture experiment. By comparing linear regressions of load vs strain plots for each type of loading, the ratio of the opening load $P$ to the machine load $P_{M}$ was found through several load-unload cycles to be:

$$
\phi=P / P_{M}= \begin{cases}3.52 & \text { graphite } \\ 2.89 & \text { no graphite. }\end{cases}
$$

All loading cycles were performed in a cold room at 
$-25^{\circ} \mathrm{C}$ and in each case the load vs strain plots were linear.

In order to determine an expression for the energyrelease rate, compliance measurements were performed on an RT-CLWL specimen made of PMMA (thickness $h=25.4 \mathrm{~mm}$, all other dimensions are given in Figure 4) at $0.05 a / L$ crack increments for $0.20 \leq a / L \leq 0.75$. Three loading trials were performed for each crack length and the average value of the three was used. Elastic response of the PMMA was ensured by zero-to-peak loading times of less than $5 \mathrm{~s}$ and all loading components were liberally coated with powdered graphite. The specimens were not loaded to fracture in any trial and all experiments were performed at $-25^{\circ} \mathrm{C}$. The load vs load point-displacement plots, as well as load vs all crack-opening displacements, were linear up to the maximum applied load in each case.

The compliance was found by a least-squares curve fit to be:

$$
\begin{gathered}
C=\frac{10^{2}}{E^{\prime} h}\left[3.29 \ln \left[(1-\alpha)^{-1}\right]-\frac{4.47}{1-\alpha}\right. \\
\left.+\frac{0.89}{(1-\alpha)^{2}}+3.53\right]
\end{gathered}
$$

where $E^{\prime}$ is the effective elastic modulus (assumed to be $3.93 \mathrm{GPa}$ for PMMA), $h$ is the specimen thickness and $\alpha=a / L$. The form for Equation (9) is similar to the approximate compliance expression for the reversetapered geometry in Mai and others (1975). The experimental data for PMMA is plotted in Figure 8 along with the least-squares curve fit; as a good fit was obtained from the above expression, derivatives of the compliance in Equation (9) were assumed to represent accurately the actual behavior. From Equation (9), the linear elastic,

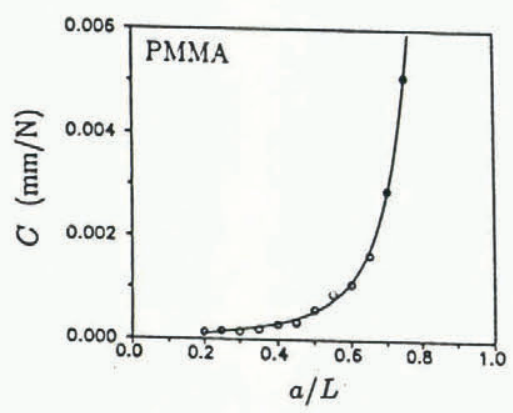

Fig. 8. RT-CLWL compliance curve for PMMA.

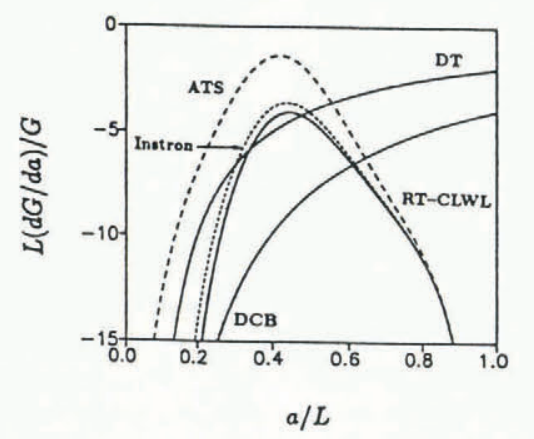

Fig. 9. Energetic stability comparison double torsion (DT), double-cantilever beam (DCB) and RT-CLWL in a rigid testing frame. Dashed line shows the effects of machine compliance on stability. isotropic relationship $K^{2}=G E^{\prime}$ and Equation (2), the fracture-resistance stress-intensity factor $K_{\mathrm{R}}$ is given by:

$$
K_{\mathrm{R}}=5 \sqrt{2} \frac{P_{\mathrm{f}}}{h \sqrt{L}} \frac{\left[3.29(1-\alpha)^{2}-4.47(1-\alpha)+1.78\right]^{\frac{1}{2}}}{(1-\alpha)^{\frac{3}{2}}}
$$

where $P_{\mathrm{f}}=\phi P_{\mathrm{M}}^{\mathrm{f}}$ is the load at fracture for the current crack length $\alpha, P_{\mathrm{M}}{ }^{\mathrm{f}}$ is the machine load at fracture and $\phi$ is the mechanical advantage given in Equation (8).

Figure 9 shows the geometric stability factors for the DT, the ideal DCB and RT-CLWL geometries. The effects of machine compliance on the RT-CLWL's GSF (ATS Model 1105SE testing frame; frame stiffness of $24.5 \mathrm{kN} \mathrm{mm}^{-1}$ ) used in this study are shown as a dashed line in Figure 9 assuming an elastic modulus of $4 \mathrm{GPa}$. Additionally, the compliance effects of a recently acquired Instron model 8502 testing frame (frame stiffness of $265 \mathrm{kN} \mathrm{mm}^{-1}$ ) are shown. The RT-CLWL is affected by machine compliance; however, crack-line wedge loading is a very easy procedure compared to the quite complex procedure of testing a weak material (like ice) with the DCB geometry. It should be noted that the elastic modulus of the material significantly affects the GSF; for warm sea ice, the effective elastic modulus is typically much less than fresh-water ice at the same temperature and, therefore, cracking in fresh-water ice should be much less stable than in sea ice. However, the advantages of a stiff testing machine are evident in Figure 9, as the GSF which includes the effects of the Instron machine compliance is close to the ideal situation of an infinitely stiff testing machine.

In a rigid testing machine, the RT-CLWL, DT and DCB fracture geometries all have negative GSFs (solid lines) for any crack length. However, due to "stick-slip" crack propagation observed in ice, continuous stable crack growth is limited to regimes of very negative $(\mathrm{d} G / \mathrm{d} a) / G$. For short cracks, all of the geometries appear to have sufficiently negative stability factors (note that the RT-CLWL does not have a physical crack until $\alpha=0.125)$. For intermediate crack lengths $(\alpha \approx 0.4)$, the GSF for the DCB is slightly more favorable for stable crack growth than the RT-CLWL and the DT; however, for long crack lengths, the RT-CLWL is most favorable for stable fracturing and, as will be noted in a later section, crack-jump increments were on the order of millimeters. For longer crack lengths, the DT and DCB geometries are increasingly unfavorable for "stick-slip" cracking materials.

\section{EXPERIMENTAL PROGEDURE}

The columnar saline ice used in this study was grown in an insulated tank $(1.22 \mathrm{~m} \times 1.14 \mathrm{~m} \times 0.78 \mathrm{~m}$ deep $)$ in a cold room by spray-seeding the chilled water surface to initiate columnar growth. The ice was grown to a depth of approximately $0.15 \mathrm{~m}$ and cut into blocks measuring approximately $0.30 \mathrm{~m} \times 0.50 \mathrm{~m} \times 0.15 \mathrm{~m}$ thick using an electric chain-saw. The average grain-size was approximately $15 \mathrm{~mm}$ and the ice had an average density at $-25^{\circ} \mathrm{C}$ of approximately $912 \mathrm{~kg} \mathrm{~m}^{-3}$. Salinity was measured using a LabComp SCT microprocessor-con- 
trolled salinity meter. The bulk salinity was found to be $7.59 \pm 1.44^{\circ} \%_{o}$. The ice blocks were immediately moved to an adjacent cold room where they were stored at $-25^{\circ} \mathrm{C}$ for a minimum of $24 \mathrm{~h}$. After the blocks were isothermal, three plates were cut from each block and were made parallel by a planer. The edges were formed by a jointer, thus ensuring that each plate was a uniform prism. To form the final shape for each RT-CLWL, the dimensions were carefully measured and then cut on a band-saw. Each finished specimen was approximately $50 \mathrm{~mm}$ thick. Drilling the $63.5 \mathrm{~mm}$ hole in each plate for the loading sectors presented special difficulties in that successively larger holes had to be drilled in order to prevent the specimen from fracturing during the drilling operation. The drilling sequence was: (i) drilling a pilot hole with a $25.4 \mathrm{~mm}$ wood spade, (ii) enlarging the hole with a $38.1 \mathrm{~mm}$ wood spade and (iii) drilling to the final diameter with a Forstner bit. Several specimens were ruined before an acceptable drilling procedure was established. The finished hole was very smooth and uniform throughout its depth, although slight spalling occurred around the circumference on the bottom face. Each completed specimen was then moved to the ATS testing frame where the COD transducers $\left(\delta_{1}\right.$ and $\left.\delta_{2}\right)$ were frozen to the top ice surface. Two small stainless steel blocks were frozen close to the point of application of the load in order to mount the load-line displacement $\left(\delta_{\mathrm{LL}}\right)$ extensometer. The blocks were indented with a conical punch to accept the centering points of the extensometer. The COD transducers were Kaman models KD2310-3U $\left(\delta_{1}\right)$ and KD2810-1U $\left(\delta_{2}\right)$ non-contacting eddy-current sensors and the load-point displacement gauge was a specially designed extensometer. A sharp crack was then made by scribing a razor blade over the crack front (DeFranco and others, 1991; Wei and others, 1991). The crack front in each specimen was parallel to the growth direction of the columnar crystals which corresponds to radial cracking of an ice sheet.

Determination of the length of each crack jump was extremely difficult due to the opacity and microstructural defects inherent in saline ice. However, a fiber-optic lighting system was used to illuminate the crack-tip area and each crack jump was measured to within a few millimeters. Fiber-optic lighting was found to work very well with ice as the optic fibers transmit minimal heat, thereby preventing any thermal cracking or melting of the ice surface. In a typical $R$-curve experiment on metals, the observable traction-free crack length cannot be taken as the actual crack length due to non-linear material behavior in the highly strained crack-tip area. The effective length of the non-linear zone is typically accounted for through the double-compliance method (Heyer and McCabe, 1972). In this method, measured crack displacements at two points on the crack face are compared to elastic-compliance functions from which an elastically equivalent crack length can be calculated. These functions are determined either by curve-fit measurements on a brittle, linear elastic material or by the finite-element method. While this technique is suitable for many materials, Bažant and others (1986) expressed doubt as to the validity of indirect compliance techniques for microcracking brittle materials in which opened microcracks do not completely close, causing opening and closing compliance to be different from the compliance for continued loading. Furthermore, in ice, crack-tip creep and/or anelastic (delayed elastic) deformation may cause uncertainties in the measured loading and unloading compliance. In this study, the traction-free crack (TFC) was taken as a first approximation to the actual crack in saline ice at $-25^{\circ} \mathrm{C}$; due to the brittlecracking behavior to be discussed in the next section, the non-linear zone is probably small enough to be ignored at this juncture.

All components of the split pins were coated with graphite and positioned in the RT-CLWL specimen taking care to ensure proper alignment with respect to the desired loading direction. All loading was accomplished by an ATS 1105SE displacement-controlled testing frame and all data were recorded by a Keithley Series 500 dataacquisition and control system. Data acquisition was performed at $100 \mathrm{~Hz}$ for tests times of $200 \mathrm{~s}$ and all data were stored in a Zenith Z248 microcomputer.

\section{RESULTS AND DISCUSSION}

In order to examine temperature effects on the fracture resistance of saline ice at slow loading rates, four RTCLWL specimens were successfully tested at $-25^{\circ} \mathrm{C}$ and three were tested at $-15^{\circ} \mathrm{C}$. All of the test data are given in Table 1 . The rate of increase of stress intensity $\dot{K}$ was

Table 1. Fracture-resistance test data

\begin{tabular}{|c|c|c|c|c|c|c|c|}
\hline \# & $\mathrm{mm}$ & $\mathrm{mm}$ & $\mathrm{mm}$ & $P_{\mathrm{f}}$ & 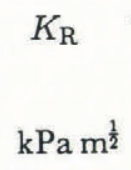 & $\begin{array}{c}\text { Temper- } \\
\text { ature } \\
{ }^{\circ} \mathrm{C}\end{array}$ & $\begin{array}{l}\text { Init- } \\
\text { iation } \\
\text { arrest }\end{array}$ \\
\hline \multirow[t]{3}{*}{ RT4 } & 47 & 254 & 105 & 296 & 105 & -25 & I \\
\hline & & & 158 & 93 & 89 & & A \\
\hline & & & 158 & 128 & 123 & & I \\
\hline \multirow[t]{6}{*}{ RT5 } & 44 & 254 & 162 & 105 & 117 & -25 & I \\
\hline & & & 185 & 52 & 104 & & A \\
\hline & & & 185 & 74 & 148 & & I \\
\hline & & & 205 & 31 & 117 & & A \\
\hline & & & 205 & 38 & 143 & & I \\
\hline & & & 217 & 23 & 144 & & A \\
\hline RT6 & 51 & 254 & 59 & 513 & 112 & & I \\
\hline \multirow[t]{5}{*}{ RT7 } & 52 & 254 & 79 & 404 & 97 & -25 & I \\
\hline & & & 134 & 185 & 97 & & A \\
\hline & & & 134 & 232 & 122 & & I \\
\hline & & & 184 & 77 & 128 & & A \\
\hline & & & 199 & 78 & 202 & & I \\
\hline RT8 & 47 & 254 & 75 & 200 & 59 & -15 & I \\
\hline \multirow[t]{6}{*}{ RT9 } & 41 & 254 & 84 & 148 & 47 & -15 & C \\
\hline & & & 85 & 194 & 63 & & C \\
\hline & & & 87 & 222 & 73 & & C \\
\hline & & & 88 & 232 & 77 & & C \\
\hline & & & 89 & 264 & 89 & & C \\
\hline & & & 91 & 303 & 104 & & C \\
\hline RT12 & 44 & 254 & 125 & 169 & 96 & -15 & I \\
\hline
\end{tabular}

I, initiation; A, arrest; C, quasi-continuous.

Note. No graphite was used on specimen RT5. 


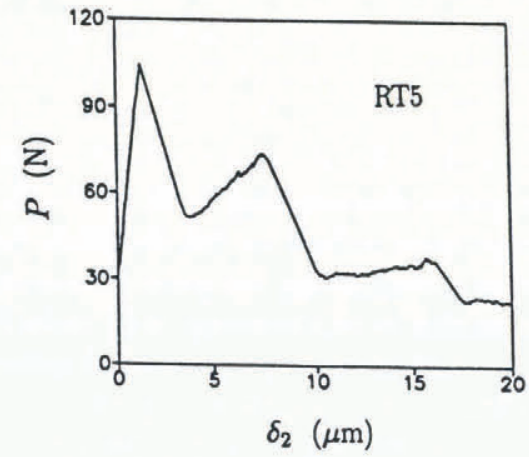

Fig. 10. $P$ vs $\delta_{2}$ at $-25^{\circ} \mathrm{C}$.

maintained at approximately $2 \mathrm{kPa} \mathrm{m}^{\frac{1}{2}} \mathrm{~s}^{-1}$ for each experiment. The difference in fracture behavior between each temperature was startling. Figure 10 shows the $P-\delta_{2}$ plot for specimen RT5 (note that $\left.\delta_{2}\right|_{\Delta a \rightarrow 0} \equiv$ CTOD). The initial slope of the curve is linear up to the instability load where crack initiation occurred, causing a rapid crack jump of $23 \mathrm{~mm} . K_{\mathrm{R}}$ at initiation was calculated from Equation (10) to be $117 \mathrm{kPa} \mathrm{m}^{\frac{1}{2}}$; the associated arrest value, also calculated from Equation (10), was found to be $104 \mathrm{kPa} \mathrm{m}^{\frac{1}{2}}$. A total of five crack jumps of lengths 23 , $23,20,20$ and $12 \mathrm{~mm}$, respectively, occurred, although only three appear on Figure 10 due to the experiment running longer than $200 \mathrm{~s}$. This behavior was typical of all specimens tested at $-25^{\circ} \mathrm{C}$ and matches the behavior observed by Parsons and others $(1988,1989)$.

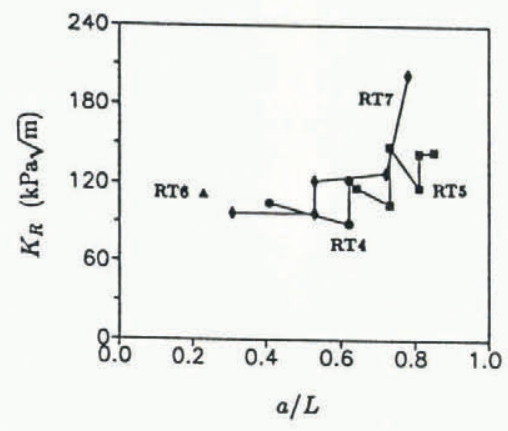

Fig. 11. $K_{\mathrm{R}}$ vs $\Delta a / L$ for saline ice at $-25^{\circ} \mathrm{C}$.

The $K_{\mathrm{R}}$ curves for specimens RT4, RT5, RT6 and RT7 (tested at $-25^{\circ} \mathrm{C}$ ) are shown in Figure 11. The overall trend shows an increasing $K_{\mathrm{R}}$ with crack growth; however, locally for each crack-jumping event, the fracture resistance decreases with increased rate of crack propagation until the crack motion arrests. As was previously found by DeFranco and Dempsey (1990) for fresh-water ice, an increase in load was needed to restart the arrested cracks. This behavior must result from the large percentage of fresh-water ice, as can be observed in the phase diagram for saline ice, which apparently dominates the mechanical behavior at cold temperatures. On the other hand, the initiation $K_{\mathrm{R}}$ values increase with crack length. Assuming that the crack arrest occurred at a grain boundary or brine channel, the reinitiation energy would most likely be higher.

The fracture behavior of saline ice at $-15^{\circ} \mathrm{C}$ was conspicuously different from the colder ice. Figure 12

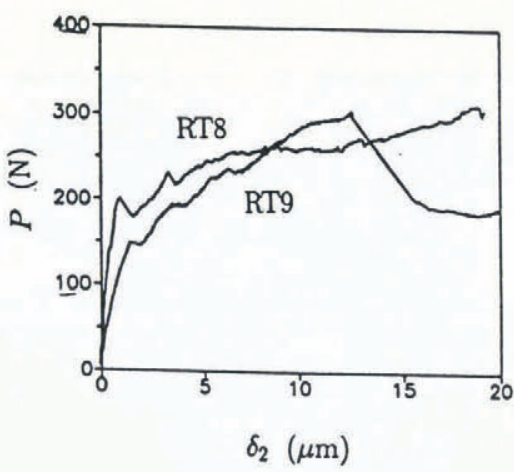

Fig. 12. $P$ vs $\delta_{2}$ at $-15^{\circ} \mathrm{C}$.

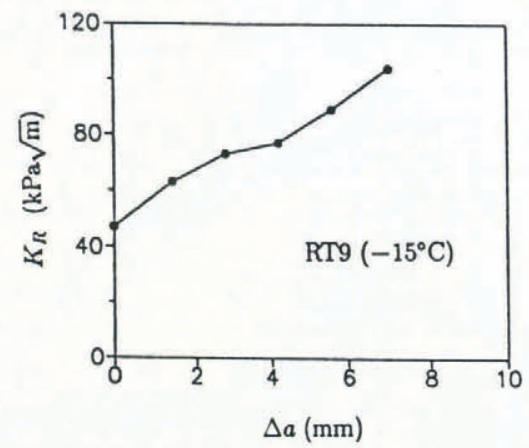

Fig. 13. $K_{\mathrm{R}}$ vs $\Delta a$ for $R T 9$.

shows $P-\delta_{2}$ plots for specimens RT8 and RT9. The plots are clearly non-linear, although for each specimen the jags in the plots coincide with small crack jumps; the large load drop in RT9 represents a large unstable crack jump which was preceded by at least five short crack jumps which total $7 \mathrm{~mm}$ in length (approximately one-half the average grain-size). This crack growth, which occurred over approximately $75 \mathrm{~s}$, was through thickness and was slow enough to be observed visually. Figure 13 shows $K_{\mathrm{R}}$ for this specimen calculated assuming each crack jump was of equal length $(1.4 \mathrm{~mm})$. The fracture resistance increases for increasing crack growth; at $\Delta a=7 \mathrm{~mm}$, however, the crack extended unstably. Interestingly, the stable crack growth initiated at an apparent fracture toughness of $47 \mathrm{kPa} \mathrm{m}^{\frac{1}{2}}$ and increased non-linearly to a critical $K_{\mathrm{R}}$ of $104 \mathrm{kPa} \mathrm{m}^{\frac{1}{2}}$. The arrest toughness was not calculated because of a highly tortuous crack path extending out of the original crack plane. Additionally, for both specimens (RT8 and RT9), reflected flecks of light were observed in areas ahead of the crack tip prior to unstable extension of the main crack, indicating the possibility of the development of a large process zone; the zone was enclosed within a semi-circle approximately $20 \mathrm{~mm}$ in diameter.

Slow, stable-fracture behavior prior to catastrophic fracture and the determination of increasing $R$-curve behavior has never been reported for ice. Parsons and others $(1988,1989)$ did not report any stable crack growth for sea ice, although test temperatures in those studies ranged from $-25^{\circ}$ to $-16^{\circ} \mathrm{C}$. A possible explanation for the lack of observed stable cracking in studies by Parsons and co-workers and Stehn $(1990,1991)$ may be that the low salinity of the sea ice tested in both studies precluded stable cracking. 


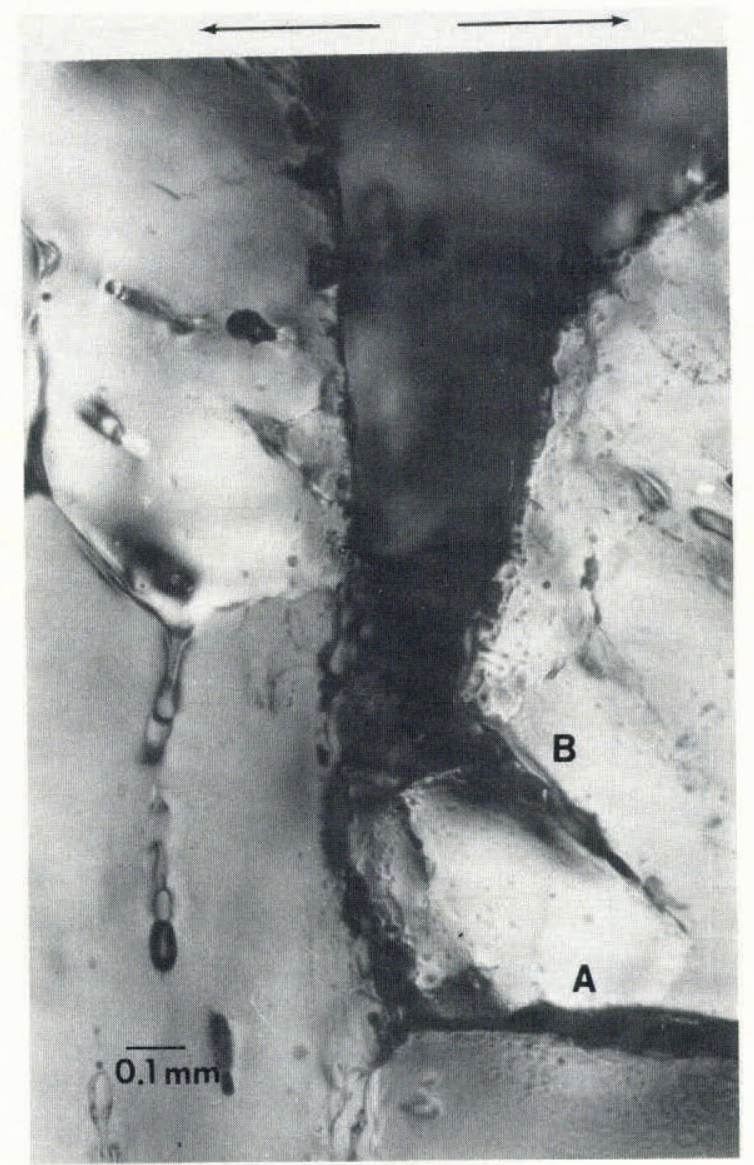

Fig. 14. Crack-tip region in specimen RT9 at 62 times magnification.

\section{MICROSTRUCTURAL INFLUENCES}

Figure 14 shows a thin section of the crack tip in RT12 $\left(-15^{\circ} \mathrm{C}\right)$ photographed through cross-polarizers at $\times 62$ with an Olympus BH-2 microscope. Several interesting features are revealed in this photograph: despite the presence of brine pockets and a grain boundary aligned with the crack, the crack propagated along a grain boundary oriented approximately perpendicular to the original crack plane (labeled A in Figure 14). Most likely, damage sustained at the grain junction during scribing of the crack tip caused the resulting fracture. Furthermore, a large pore may have existed at this location, forcing the scribed crack to extend along the grain boundary. Only a pre-test thin section of the near-tip area (which was not done) would confirm this possibility. Additionally, a crack (B in Figure 14), which was probably generated during scribing of the main crack, did not propagate, indicating a larger damage structure must have existed on the actual fracture plane. Figure 15 shows a lowermagnification photograph $(\times 5)$ of the same area; fracture in this specimen was predominantly intergranular (grain boundary). This does not agree with the findings for experiments performed using three-point bend specimens of similar ice at $-25^{\circ} \mathrm{C}$ (DeFranco and others, 1991). In that paper, the crack path tended to follow the sub-grain pore arrangement (i.e. along the basal planes), in some instances changing direction suddenly in order to propagate along the basal direction. In Figures 14 and 15 , the tensile opening loads were applied in the direction shown by the arrows at the top of the photographs.

The discussion in this paper is based upon the stability Equation (1); the polycrystalline ice is seen from a macroscopic point of view as an equivalent homogeneous medium. As revealed by the above discussion, the actual fracture mechanisms are dramatically influenced by temperature and the microstructure in the vicinity of the crack tip. Given the restrictions imposed on the specimen sizes that can be tested in the laboratory, crack length vs grain-size or some such characteristic length is an important issue. This issue has been addressed by the authors in previous papers (Dempsey, 1991; Dempsey and others, 1991, 1992) in the context of notch sensitivity and polycrystallinity vs single-cum-multiple specimen sizes. The stability issues are, of course, inextricably intertwined with the issues of notch sensitivity, brittleness and polycrystallinity.

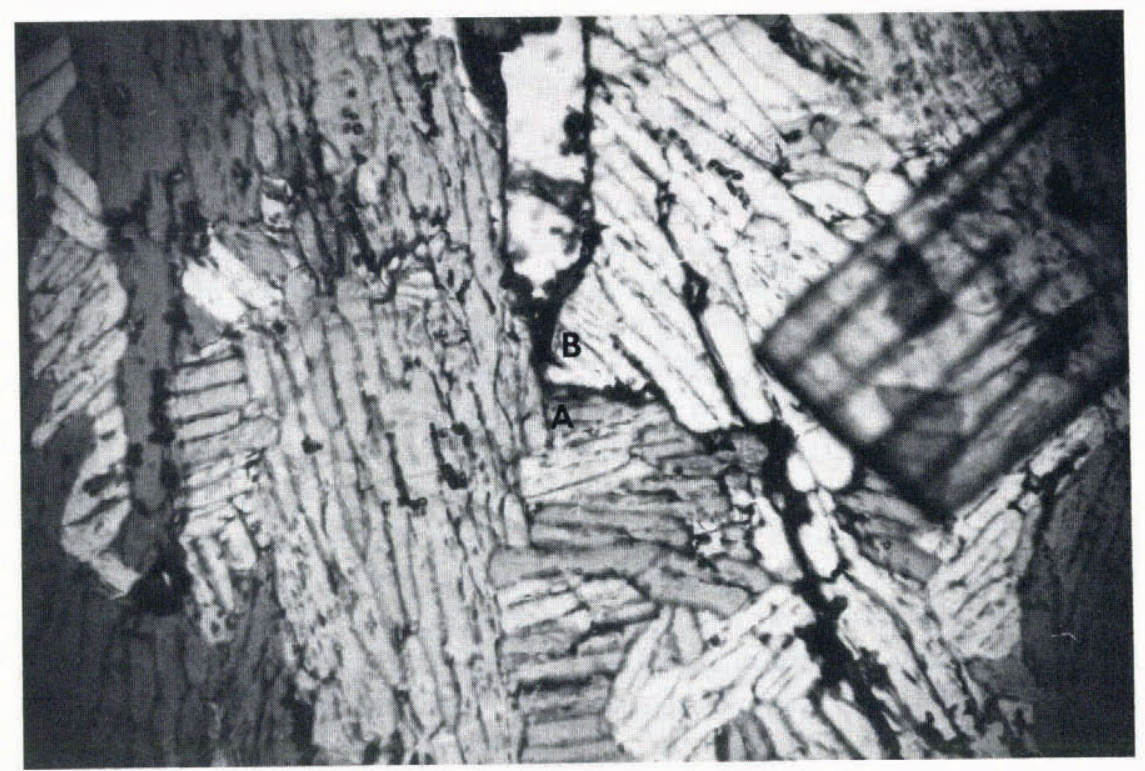

Fig. 15. Crack-tip region in specimen RT9 at 5 times magnification (scale gradations are $1 \mathrm{~mm}$ ). 


\section{CONGLUSIONS}

A new fracture geometry, the reverse-tapered crack-line wedge load (RT-CLWL) was developed and utilized to produce stable crack growth in saline ice.

RT-CLWL fracture experiments on saline ice at $-25^{\circ} \mathrm{C}$ showed brittle "stick-slip" fracture behavior. The fracture resistance for each "stick-slip" crack event was found to decrease during crack propagation to a crackarrest value lower than that needed for crack re-initiation. The fracture resistance for crack re-initiation was found to be much higher than the previous crack-arrest value. Comparison of the re-initiation fracture-resistance values with crack growth indicates a globally positive $K_{\mathrm{R}}$ curve.

Subsequent experiments on saline ice at $-15^{\circ} \mathrm{C}$ exhibited more ductile behavior. In these tests, loaddisplacement plots exhibited a greater degree of nonlinear behavior throughout the fracture experiment. Slow crack growth was observed up to a critical load which coincided with a long unstable crack jump. During the stable cracking, the fracture resistance increased nonlinearly with crack growth.

The positive $K_{\mathrm{R}}$ vs $\Delta a$ behavior found for both cold and warm saline ice indicates that stable cracking should readily occur in warm sea ice, while for cold sea ice "stick-slip" cracking will occur provided that conditions conducive to stable cracking are maintained.

\section{ACKNOWLEDGEMENTS}

This work was supported in part by the U.S. Office of Naval Research under grant N00014-90-J-1360, in part by the U.S. National Science Foundation under grants MSM-86-18798 and MSS-90-079291, and in part by the Mobil Research and Development Corporation.

The authors thank Mr P.J. Parker and Mr R. J. Cary for their assistance in developing the RT-CLWL fracture geometry and in performing the experiments. Mr Parker and $\mathrm{Mr}$ Cary were supported by the U.S. National Science Foundation's Research Experience for Undergraduates Program under grant MSM-86-18798. The authors also thank Dr B. L. Parsons, Institute for Marine Dynamics, St. John's, Newfoundland, for his helpful comments concerning this paper.

\section{REFERENCES}

American Society for Testing and Materials. 1960. Fracture testing of high strength materials. ASTM Bulletin, 243(29). (Special Committee Report.)

American Society for Testing and Materials. 1987. R-curve determination. In ASTM Stds 03.01. Philadelphia, PA, American Society for Testing and Materials, 571-582. (E561-86.)

Assur, A. 1963. Breakup of pack-ice floes. In Kingery, W. D., ed. Ice and snow; properties, processes, and applications. Cambridge, MA, M.I.T. Press, 335-347.

Bažant, Z.P., J.-K. Kim and P. A. Pfeiffer. 1986. Nonlinear fracture properties from size effect test. J. Struct. Eng., 112, 289-307.

Bentley, D. L. 1988. Fracture of freshwater and urea model ice. (Ph.D. thesis, Clarkson University.)

Bhat, S. U. 1988. Analysis for splitting of ice floes during summer impact. Cold Reg. Sci. Tech., 15(1), 53-63.

Bhat, S. U., S. K. Choi, T. Wierzbicki and D. G. Karr. 1989. Failure analysis of impacting ice floes. In Sinha, N. K., D. S. Sodhi and J. S. Chung, eds. Proceedings of the Eighth International Conference on Offshore
Mechanics and Arctic Engineering ... The Hague, The Netherlands, March 19-23, 1989. Vol. 4. Arctic and polar technology. New York, American Society of Mechanical Engineers, 275-285.

DeFranco, S. J. and J. P. Dempsey. 1990. Crack growth stability in S2 ice. In IAHR. The 10th Symposium on Ice, August 20-24, 1990. Espoo, Finland. Proceedings. Vol. 1, Espoo, Helsinki University of Technology, 168-181.

DeFranco, S. J. and J. P. Dempsey. 1991. Crack growth stability in saline ice. In Cocks, A. C. F. and A. R. S. Ponter, eds. Mechanics of creep brittle materials. Vol. 2. New York, Elsevier Applied Science, 25-36.

DeFranco, S. J., Y. Wei and J. P. Dempsey. 1991. Notch acuity effects on the fracture toughness of saline ice. Ann. Glaciol., 15, 230-235.

Dempsey, J. P. 1991. The fracture toughness of ice. In Jones, S. J., R. F. McKenna, J. Tillotson and I. Jordaan, Jr, eds. Ice-Structure Interaction. IUTAM/IAHR Symposium, St. John's, Newfoundland, Canada, 1989. Berlin, Springer-Verlag, 109-145.

Dempsey, J. P., D. L. Bentley and D. S. Sodhi. 1986. Fracture toughness of model ice. In IAHR. Symposium on Ice 1986, Iowa City, August 18-22, 1986. Proceedings. Vol. 1. Iowa City, IA, University of Iowa. Institute of Hydraulic Research, 365-376.

Dempsey, J. P., Y. Wei, S. DeFranco, R. Ruben and R. Frachetti. 1989. Fracture toughness of S2 columnar freshwater ice: crack length and size specimen size effects - part II. In Axelsson, K. B. E. and L. $\dot{A}$. Fransson, eds. POAC 89. The 10th International Conference on Port and Ocean Engineering under Arctic Conditions, June 12-16 1989, Lulea, Sweden. Volume 1, Luleå, Tekniska Högskolan i Luleå, 199-207.

Dempsey, J. P., Y. Wei and S. J. DeFranco. 1991. Fracture resistance to cracking in ice: initiation and growth. In Sodhi, D.S., ed. Cold regions engineering. Proceedings of the Sixth International Specialty Conference ... West Lebanon, $\mathcal{N} H$, February 26-28, 1991. New York, American Society of Civil Engineers, 579-594.

Dempsey, J. P., Y. Wei and S. J. DeFranco. 1992. Notch sensitivity and brittleness in fracture testing of S2 columnar freshwater ice. Int. F. Fract., 53, 101-120.

Dyer, I. 1988. Arctic ambient noise: ice source mechanics. Phys. Today, 41, S.5-S.6.

Farmer, D. M. and Y. Xie. 1989. The sound generated by propagating cracks in sea ice. f. Acoust. Soc. Am., 85(4), 1489-1500.

Gold, L. W. 1963. Crack formation in ice plates by thermal shock. Can. f. Phys., 41(10), 1712-1728.

Gurney, C. and J. Hunt. 1967. Quasi-static crack propagation. Proc. $R$. Soc. London, Ser. A, 361, 254-263.

Heyer, R.H. and D.E. McCabe. 1972. Plane-stress fracture toughness testing using a crack-line-loaded specimen. Eng. Frac. Mech., 4, 393-412.

Irwin, G.R. 1961. Fracturing and fracture mechanics. Urbana, IL, University of Illinois. (T. and A.M. Report 202.)

Irwin, G. R. and J.A. Kies. 1954. Critical energy rate analysis of fracture strength. Weld. Res. Suppl., XIX, 193-s -198-s.

Kanninen, M. F. 1973. An augmented double cantilever beam model for studying crack propagation and arrest. Int. F. Fract., 9, 413-430.

Kendall, K. 1978. Complexities of compression failure. Proc. R. Soc. London, Ser. A, 361, 245-263.

Ketcham, W. M. and P. V. Hobbs. 1969. An experimental determination of the surface energies of ice. Philos. Mag., 19(162), 1161-1173.

Mai, Y.-W. and A. G. Atkins. 1980. Crack stability in fracture toughness testing. 7. Strain Anal., 15, 63-74.

Mai, Y.-W., A. G. Atkins and R. M. Caddell. 1975. On the stability of cracking in wedge tapered DCB specimens. Int. J. Fract., 11, 939-953.

Parsons, B. L., J.B. Snellen and D.B. Muggeridge. 1988. The indentation and arrest stress intensity factors of first year columnar sea ice. In Saeki, H. and K.-i. Hirayama, eds. IAHR Proceedings. The 9th International Symposium on Ice, 23-27 August 1988, Sapporo, Japan. Vol. 1. International Association for Hydraulic Research. Committee on Ice Problems, 502-511.

Parsons, B. L., J. B. Snellen and D. B. Muggeridge. 1989. The double torsion test applied to fine grained freshwater columnar ice and sea ice. In Cocks, A. C. F. and Ponter, A. R. S., eds. Mechanics of creep brittle materials. Vol. 1, Elsevier Applied Science, New York, 188-200.

Peck, L., C. C. Barton, and R. B. Gordon. 1985. Microstructure and the resistance of rock to tensile fracture. 7. Geophys. Res., 90(B13), 11,533-11,546.

Planas, J. and M. Elices. 1990. Size effect in concrete structures: mathematical approximations and experimental validification. In Mazars, J. and Z. P. Bažant, eds. Cracking and damage, Elsevier, New York, 462-476.

Sammis, C. G. and M. F. Ashby. 1986. The failure of brittle porous solids under compressive stress states. Acta Metall., 34, 511-526.

Selby, K. and L. E. Miller. 1975. Fracture toughness of and mechanical behavior of an epoxy resin. 7. Mater. Sci., 10, 12-24. 
Stehn, L. 1990. Fracture toughness of sea ice. (Licentiate thesis, Luleà University of Technology).

Stehn, L. 1991. Fracture toughness of low salinity sea ice using short rod chevron notched specimens. In Muggeridge, D. B., D. B. Colbourne and H. M. Muggeridge, eds. POAC'91. The 11th International Conference on Port and Ocean Engineering under Arctic Conditions, September 24-28, 1991, St. John's, Canada. Proceedings. Vol. 1. St. John's, Memorial University of Newfoundland. Ocean Engineering Research Centre, 541-555.
Wei, Y., S.J. DeFranco and J. P. Dempsey. 1991. Crack-fabrication techniques and their effects on the fracture toughness and CTOD for fresh-water columnar ice. f. Glaciol., 37(126), 270-280.

Xie, Y. and D. M. Farmer. 1991. Acoustical radiation from thermally stressed sea ice. F. Acoust. Soc. Am., 89(5), 2215-2231.

The accuracy of references in the text and in this list is the responsibility of the authors, to whom queries should be addressed.

MS received 27 July 1992 and in revised form 29 April 1993 